\title{
Molybdenum as an Essential Element for Crops: An Overview
}

\author{
Muhammad Shoaib Rana ${ }^{1,2}$, Parashuram Bhantana ${ }^{1,2}$, Xue-cheng Sun ${ }^{1,2}$, Muhammad Imran ${ }^{1,2}$ \\ Muhammad Shaaban ${ }^{3}$, Mohamed G. Moussa ${ }^{1,2}$, Muhammad Hamzah Saleem ${ }^{4}$, Ali Mohamed Elyamine ${ }^{1,2}$, \\ Rana Binyamin ${ }^{5}$, Mufid Alam ${ }^{6}$, Javaria Afzal ${ }^{1,2}$, Imran Khan ${ }^{1,2}$, Intisar Ud Din ${ }^{1,2}$, Ilyas Ahmad ${ }^{7}$, Muhammad \\ Younas $^{1,2}$, Muhammad Kamran ${ }^{1,2}$ and Cheng-xiao $\mathrm{Hu}^{1,2 *}$
}

${ }^{1}$ Key Laboratory of Arable Land Conservation (Middle and Lower Reaches of Yangtze River), Ministry of Agriculture, Micro-elements Research Center, College of Resource and Environment, Huazhong Agricultural University, Wuhan 430070, China

${ }^{2}$ Hubei Provincial Engineering Laboratory for New Fertilizers, Huazhong Agricultural University, Wuhan 430070, China

${ }^{3}$ Department of Soil Science, Bahauddin Zakariya University, Multan, Pakistan

${ }^{4}$ College of Plant Science, Huazhong Agricultural University, Wuhan 430070, China

${ }^{5}$ University of Agriculture Faisalabad Sub Campus Burewala Vehari, Pakistan

${ }^{6}$ National Key Laboratory of Crop Genetic Improvement, College of Life Science and Technology, Huazhong Agricultural University, Wuhan 430070, China

${ }^{7}$ Soil and Water Testing Laboratory for Research, Multan, Pakistan

*Corresponding author: Cheng-xiao Hu, Key Laboratory of Arable Land Conservation (Middle and Lower Reaches of Yangtze River), Ministry of Agriculture, Micro-elements Research Center, College of Resource and Environment, Hubei Provincial Engineering Laboratory for New Fertilizers, Huazhong Agricultural University, Wuhan 430070, China

\section{ARTICLE INFO}

Received: 㓞 December 20, 2019

Published: 幽 January 21, 2020

Citation: Muhammad Shoaib Rana, Parashuram Bhantana, Xue-cheng Sun, Muhammad Imran, Muhammad Shaaban, Mohamed G. Moussa, Muhammad Hamzah Saleem, Ali Mohamed Elyamine, Rana Binyamin, Mufid Alam, Javaria Afzal, Imran Khan, Intisar Ud Din, Ilyas Ahmad, Muhammad Younas, Muhammad Kamran, Cheng-xiao Hu. Molybdenum as an Essential Element for Crops: An Overview. Biomed J Sci \& Tech Res 24(5)-2020. BJSTR. MS.ID.004104.

Keywords: Molybdenum; Nitratereductse; Aldehyde Oxidase; Xanthine Dehydrogenase; Sulfite Oxidase; Mitochondrial Amidoximereductase; Inefficiency; Toxicity

\section{ABSTRACT}

Background: Molybdenum for plant growth is essential micronutrient wherever in enzyme catalysis it is required as catalytically active metal. Functional roles are fulfilled by molybdenum in enzyme systems in plants. Enzymes more than 50 Mo-containing are recognized, maximum of them are of bacterial origin, while a few Mo-enzymes are seen amongst eukaryotes. Five Mo-enzymes in plants, to this end are identified: AO, NR, SO, mARC and XDH which catalyze vital significant reactions in degradation of purine, synthesis of phytohormone, nitrogen assimilation and detoxification of sulfite.

Scope: The enzymes are significant regardless of having common structural elements, in the series of diverse chemical reactions those are being catalyzed, even though nearly all reactions are two electron oxidation reduction in this an atom of oxygen is transferred from or to the Mo. XDH family enzymes are described best mononuclear enzymes having molybdenum. This article will emphasis on computational approaches to those plant enzymes which requisite Mo as catalytic metal, focusing on their functions, key mechanisms, current prospects and future challenges.

Conclusion: Plants distress from deficiency of Mo is limited in growth and development, their leaves shows paleness, disorders in flower formation and ultimately withers. So, molybdenum nutrition for healthy growth and development of plant is key essential where it is being obligatory as a metal that is catalytically active in catalysis of enzymes (NR, SO, XDH, AO and mARC) that accomplishes functional roles in plants enzyme systems and known to participate in numerous redox reactions and results in proper plant growth and development while they have significant positions both in the redox biogeochemical cycles of $\mathrm{N}, \mathrm{S}$ and $\mathrm{C}$ on earth and in the individual organism metabolism.Thus, prompt improvement in our understanding of Mo enzymes role and function in plants will help us that how it will be helpful for the proper plant functioning regarding their responses and metabolism. 


\section{Introduction}

Molybdenum in enzymes as catalytic center has chemical adaptability, which is valuable to biological systems, in physiological conditions, it is redox-active. To catalyze diverse redox reactions molybdenum, possess versatile redox chemistry which is utilized by enzymes. At enzyme environment and Mo atom, this redox chemistry is controlled both by different ligands [1]. The molybdate anion in soils is the only Mo form available to plants. For life enzymes having Mo are of vital importance, subsequently they have significant positions both in the redox biogeochemical cycles of $\mathrm{N}$, $\mathrm{S}$ and $\mathrm{C}$ on earth and in the individual organism metabolism [2-4]. More than 50 Mo-containing enzymes are known to be Mo-dependent, Mo five enzymes in plants still are known: sulfite oxidase

Table 1: Mo enzyme in plant (Arabidopsis thaliana).
(SO), mARC (mitochondrial amidoxime reductase), XDH (xanthine dehydrogenase), NR (nitrate reductase) and AO (aldehyde oxidase) Table $1[5,6]$. In cytosol NR is localized that catalyses the nitrate into nitrite reduction. By NiR (nitrite reductase) that is to be found in plastids, into ammonium nitrite is reduced and into amino acids this ammonium via GSGOGAT cycle this is further assimilated. In assimilation pathway of nitrate as NR is the key primary enzyme that is why in plants deficiency of Mo often leads to $\mathrm{N}$ deficiency. To peroxisome SO is localized that oxidizes the sulphite (toxic) into sulphate, in opposite way to the assimilation of reductive sulphate that take place in plastids [7]. For purine degradation XDH is required in $\mathrm{N}$-metabolism and can produce ROS (reactive oxygen species) and AO takes part in ABA (abscisic acid) synthesis, glucosinolates, auxin, and probably, further compounds in plants [8-11].

\begin{tabular}{|c|c|c|c|c|}
\hline Mo enzyme & Number of Genes & Subcellular Location & Function & ROS/RNS Side Product \\
\hline Nitrate reductase & 2 & Cytosol & Nitrate assimilation & NO \\
\hline Sulfite oxidase & 1 & Peroxisome & Sulfite detoxification & $\mathrm{H}_{2} \mathrm{O}_{2}$ \\
\hline Xanthine dehydrogenase & 2 & Cytosol & Purine degradation, NADH oxidase & Superoxide anions \\
\hline Aldehyde oxidase & 4 & Cytosol & Synthesis of ABA (Auxins) & $\mathrm{H}_{2} \mathrm{O}_{2}$, Superoxide anions \\
\hline Mitochondrial amidoxime reductase & 2 & Mitochondria & Detoxification (?) & n.d \\
\hline
\end{tabular}

In divergence to other Mo containing enzymes, eukaryotic mARC (Mitochondrial amidoximereductase) proteins does not show enzymatic action their own but needs other proteins like NADH/ cytochrome $_{\mathrm{b5}}$ and cytochrome ${ }_{\mathrm{b} 5}$ reductase as transmitters electron and donor's electron, respectively (Mendel, 2011). Once molybdate come into the cell it is consequently integrated through the complex biosynthetic machineries into metal cofactors. Then these metal cofactors into different enzymes are incorporated [12]. There are two molybdoenzyme distinctive forms, molybdenum nitrogenase have unique cluster molybdenum-iron-sulfur, called FeMoco [13]. The reduction of atmospheric dinitrogen to ammonia is catalyzes by nitrogenase. Other molybdoenzymes are oxidoreductases that transmit two electrons or an oxo group to or from substrate. They possess Mo cofactor in that Mo is coordinated to a dithiolene group on pterin 6-alkyl side chain called MPT (molybdopterin) $[14,15]$. This review will concentrate on computational approaches to enzymes containing Mo, focusing on their functions, key mechanisms, current prospects and future challenges.

\section{Symptoms of Molybdenum Deficiency and Molybdenum}

\section{Excess in Crops}

Molybdenum insufficiencies predominantly related with poor $\mathrm{N}$ health mainly when nitrate is major available $\mathrm{N}$ form for growth of plant. Plants distress from deficiency of Mo is limited in growth and development, their leaves shows paleness, disorders in flower formation and ultimately withers. In dicotyledons irregularities in formation of leaf blade (whiptail) and severe decline in size are being seen the most visual typical symptoms. These are due to vascular bundles insufficient differentiation on initial leaf development phases and the local necrosis in tissue [16]. Mo insufficient plants have characteristic phenotype containing altered morphology of leaves and lesions [17]. In maximum plant species, the NR activity loss is related with nitrate increased tissue concentrations and reduction in yields and growth of plant [18].In view of that, in the plants of spinach that is grown under deficiency of Mo, activity of leaf NR was reduced and final yields of plant was lesser than that of control where adequate amount of Mo received by plant. In wheat, Mo insufficiency also indicated decreased activities of NR regardless of NR regulatory control by dark and light periods $[19,20]$. Mo resupply as foliar or in nutrient solution in most cases recovers activity of NR [19]. In Vitis vinifera, during establishment poor growth and in mature plants variable yields grown in various vineyards of South Australian is positively interrelated with reduced petiolar levels of molybdenum [21].

At various diverse levels deficiency of Mo affects plant metabolism. The responses intensely associated to the Mo requirement for numerous molybdoenzymes types existing in the plants. Deficiency of Mo may also be due to a mutation in particular Mo uptake system [22-24]. Defect in biosynthesis of Moco, can cause Mo deficiency that has intense consequences for cell because all Mo containing enzymes activities pleiotropically are strongly reduced or lost. Molybdoenzymes of plant could be split down to those involved in $\mathrm{N}$ assimilation and reduction i.e. nitrate reduction (NR), nitrogen fixation (nitrogenase), indole- 3 acetic acid (IAA) synthesis (AO), abscisic acid (ABA),sulfur metabolism (SO) and purine catabolism (XDH). SO and NR comprise of dioxo Mo cofactor, that stimulates protein when in protein complex, it is inserted (Mendel 
and Haensch, 2002). AO and XDH have a monoxo Mo cofactor that needs Moco insertion and after that following Mo centre sulfuration to stimulate complex Moco/protein [25-27]. AAO3 is essential for transformation of the abscisic aldehyde into $\mathrm{ABA}$, therefore that one loss cause wilty phenotype that is severe for plant survival $[28,29]$. Whereas a knockout in one of two mARC proteins have not any evident phenotype and deficiency of Moco-sulfurase (ABA3) was seen to be mainly recognized to ABA levels reduction due to absence of activities of AOand therefore wilty phenotype [30]. Since Mo is takes part in different enzymatic processes, a clear plant reaction to deficiency of Mo could be complex and therefore tough to allocate causally to particular enzyme systems. In molybdoenzymes this is mainly evident involved in metabolism of $\mathrm{N}$ where overall reductions plant health and growth can modify development of plant, grain or fruit development and pest damage susceptibility [31].

Molybdenum insufficiency causing the deficiency of $\mathrm{N}$ in legumes that are relying on fixation of $\mathrm{N} 2$ is widespread, principally in the acidic mineral soils of sub humid and humid tropics. The reports indicated that Mo foliar applications in the field conditions to the grain legumes upsurge nodule mass and N2 fixation levels, that results in overall high seed yield and $N$ content [32]. In the laboratory circumstances, numerous legumes that were severely Mo starved exhibited more dramatic deficiency signs. This is also being described that Mo transport deficient B. japonicum strain exhibited reduced fixation activity of $\mathrm{N}$ when it is inoculated to roots of soybean. In Vitis vinifera during establishment variable

\section{Functions of Molybdenum in Plants}

yields and poor growth in the mature plants in various vineyards of South Australian is interrelated positively with reduced petiolar Mo levels [21].

In contrast, toxicity of Mo in maximum agricultural conditions in plants is rare. Mo toxicity and availability to plants is strappingly reliant on properties of soil and its occurrence as anionic species, so plants take $\mathrm{Mo}$ in molybdate anions form $\left(\mathrm{MoO}_{42}{ }^{-}\right.$and $\left.\mathrm{HMoO}_{4}^{-}\right)$ that are in soil solution, predominant species [33,34]. At low $\mathrm{pH}$ protonation takes place where $\mathrm{H}_{2} \mathrm{MoO}_{4}$ (diprotonated monomer) and $\mathrm{HMoO}_{4}-$ (monoprotonated monomer) can perform a related role. The grouping of three monomer species and isopolymolybdates three other (protonated heptamer, heptamer and octamer) interprets in equilibrium for all species in aqueous solutions having pH 2-7 and concentrations of molybdate amongst $0.03 \mathrm{mM}$ and 0.1 M. Though, for soils havingpH more than 4.0, $\mathrm{MoO}_{42}$ - is principal available form [35]. Properties of soil like amorphous iron (Fe), texture, Al hydroxides / oxides, and O.M could also affect Mo uptake by plants. [36,37] demonstrated the soil properties significance on the bioavailability and toxicity of metal cations that are divalent as $\mathrm{Cu}, \mathrm{Co}$ and $\mathrm{Ni}$. But, contrasting to cationic metals, generally Mo availability to higher plant species upsurges with increasing $\mathrm{pH}$ of soil. [38] determined that Pisum sativum L. plants the Mo highest concentration ( $1 \mathrm{mM}$ ) tested inhibited yield of shoot and root respectively, by $35 \%$ and $50 \%$, Besides conditions of soil solution and properties of soil, plants Mo accumulation is also reliant on the plant species e.g. Brassica species are recognized to accumulate Mo [39-41].

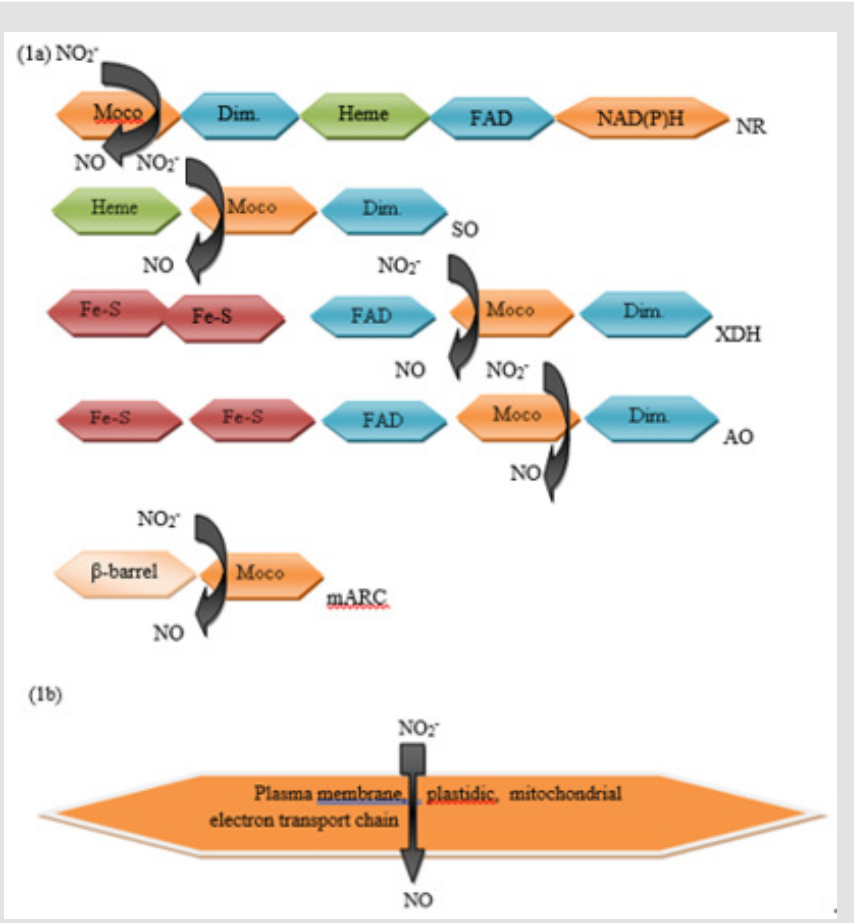

Figure 1: From NO (Nitrite) enzymes anticipated to yield nitric oxide. Through catalytic Moco domain Mo-enzymes proposed to facilitate NO production (2a) while extra systems that also have been suggested to facilitate the NO production (2b) (Sakihama et al. [42-46). 
In plants, Mo-enzymes NR, SO, XDH, AO and mARC have key essential functions [6]. Figure 1; From NO (Nitrite) enzymes anticipated to yield nitric oxide. Through catalytic Moco domain Mo-enzymes proposed to facilitate NO production (1a) while extra systems that also have been suggested to facilitate the NO production (1b) [42-46]. For different Mo-enzymes in production of NO, nitrite been proposed to be a substrate, can be in use up by cells, but is mainly the nitrate reduction product at the NR active center (Figure 1) [47]. Plants Mo-enzymes into two families are classified dependent on how Moco binds to the active site of enzyme, either covalently by an enzyme cysteine thiol group (NR, SO, and ARC) or by means of an inorganic sulfur (XDH and AOX). In NR, AO, SO, mARC, $\mathrm{XDH}$ all of the activities of NO-synthesizing has been revealed to be active under anaerobiosis and in vitro by use of nitrite as a substrate $[13,45,46]$. These have very crucial role for growth optimization, yield and development of plants, their key importance and crucial role in proper plant functioning is described below.

\section{NR and Its Function}

NRs are enzymes by which nitrate assimilation catalyze, nitrate reduction to nitrite by means of a Mo cofactor. In an alternate reaction, plant NRs have also revealed to catalyze nitrite reduction to nitric oxide, and this seems in plant to be a main source for synthesis of nitric oxide [48]. DFT (Density functional theory) results showed that although for NR active site nitrate is thermodynamically the preferable substrate, nitrate and nitrite both easily reduced to NO and nitrite, respectively. Mo (IV) state is needed by these mechanisms. Moreover, in nitrite case, linkage isomerism is at work and controlled by oxidation state of metal and reduction is, unlike in the case of nitrate, dependent upon protonation. As thereby NR to plant provides essential $\mathrm{N}$ metabolites, it is evident that NR deficient plants are no longer $\mathrm{N}$ autotroph and depend on $\mathrm{N}$ alternate sources as like ammonium. The NR monomer comprises of distinct three domains [49]: with Moco N-terminal domain linked, and domain FAD-binding with C-terminal, domain cytochrome ${ }_{\mathrm{b} 5}$ with the central heme-binding, whereby such two monomers form active homodimeric enzyme. Enzyme substrates standard redox potentials $\left(\mathrm{Eo}^{\prime}\right)$ and prosthetic groups of the enzyme involved are shown in Figure 2 [50]. Electron is indicated by arrows from NADPH to nitrate by numerous prosthetic groups with a favorable electrochemical potential gradient. These prosthetic groups are bound to isolated domains of protein that are interconnected through hinge flexible regions. By regions protease sensitive hinge these domains are linked called hinge I and II. Hinge I in plants, the linker among Moco and cytochrome ${ }_{b 5}$ domain, has a conserved serine residue which intervenes interaction with protein 14-3-3 when phosphorylated, consequently leading to enzyme activity inhibition [51].

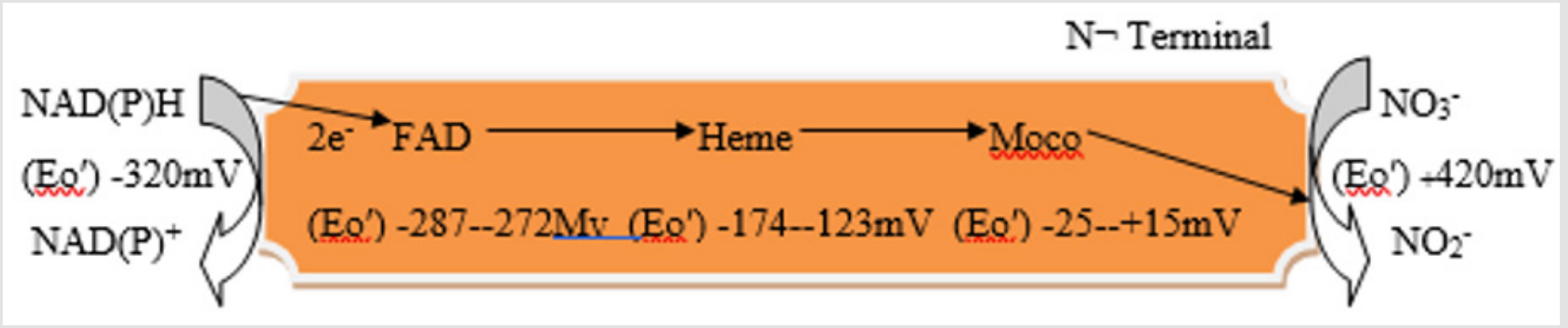

Figure 2: NR ETC scheme.

Nitrate assimilation regulation is part of network that is complex regulatory replying to internal signals and diverse environment as like metabolites of $\mathrm{C}$ and $\mathrm{N}$, metabolism nitrate, $\mathrm{CO}_{2}$, light, and phytohormones, in order to coordinate assimilation of nitrate with other significant metabolic processes $[52,53]$. The NR regulation includes both post translational and transcriptional mechanisms that are regulating the amount as well as NR protein activity. NR protein is phosphorylated in dark, thus allowing NR inhibitor protein stoichiometric binding that belongs to 14-3-3 class proteins [51]. On leaves illumination, by dephosphorylation and dissociation of the inhibitor protein NR is rapidly reactivated. Dephosphorylated NR cannot be inhibited by inhibitor protein. Starting at nitrate transporters, signal transduction flow and nitrate linking availability to the transcription induction is still mysterious, but in research receives a lot of attention nowadays. There are signs that nitrate not only serves as substrate for assimilation, but also for coordinating $\mathrm{C}$ and $\mathrm{N}$ metabolism as regulatory signal and driving root development [54-58].
NR efficient turnover as nitrate reductase as conflicting to nitrite reductase duty depend either on nitrite efficient expulsion from active site, or onto the electronic structure distinctiveness of the active site of Mo that will favor nitrate reduction and binding over nitrite reduction and binding [59]. In current years nitrate reduction has been computationally explored at Mo center of NR, from crystal structure data particularly benefiting [60]. Around active site, significant amino acids were recognized, and their role in fine-tuning reactivity towards the electrons and nitrate were explored in some detail [61]. By NR the nitrite reduction exact mechanism is unknown. This mechanism might include coordination of nitrite via one or two oxygen atoms, or via $\mathrm{N}$. As another plant NR regulatory region, $\mathrm{N}$ terminal extension preceding the Moco domain was shown to be involved in the posttranscriptional regulation by light [62]. NR specific forms NADH in higher plants are most abundant; however specific forms NADPH occur among fungi $[63,64]$. It is significant that inside protein Moco is completely buried and cone like structure leads from the protein 
surface to active site. Whereas in nitrogen assimilation nitrite is further reduced to ammonium by nitrite reductase in chloroplasts, by NR itself it can also be reduced to signaling molecule nitric oxide (NO) [65]. As NR post-translational modification also modulated the rates of NO production, it was determined that indeed NR is a active nitrogen species producer also in vivo [66]

Accordingly, grown under Mo deficiency disorders in spinach plants, NR activity in the leaf was found to be decreased and final plant yields grown on sufficient levels of Mo, overall lower than control plants $[18,19]$. Mo insufficiency in wheat, was also revealed to reduce maximum activities of NR irrespective of the NR regulatory control through periods dark and light [67]. As foliar spray Mo resupplying or in nutrient solution supplemented in maximum instances will recover readily NR activity [19]. In Merlot phenotype present it would indicate not related to activity and synthesis of Moco or NR apoenzyme but associated with a disturbance in mechanism that are monitoring Mo uptake or inner redistribution in phloem and xylem [22].

\section{AO and Its Function}

$\mathrm{AO}$ enzymes are alike to XDH upon an early gene duplication that is derived from XDH. Coextensive with this, both enzymes show a high degree use of same prosthetic groups and sequence similarity which catalyze the oxidation of a variety of nonaromatic and aromatic aldehydes and heterocycles, so converting them to respective carboxylic acid as they share a more degree of sequence homology, so that during evolution it is presumed that from XDH, $\mathrm{AO}$ has been derived by neo-functionalization and gene duplication. Then XDH, AOs display a greatly substrate specificity, covering aldehydes, aliphatic and aromatic heterocycles as well as pteridines and purines while $300 \mathrm{kDa}$ apparent molecular mass and therefore with XDH shares structural and catalytical similarities. AO proteins in contrast to $\mathrm{XDH}$ preferably oxidize aldehydes to respective carboxylic acid. Furthermore, during catalysis molecular oxygen is exclusive electron acceptor and its consumption is obligatorily linked with the generation of hydrogen superoxide and peroxide anions $[9,68]$. However, main differences are present regarding the binding of substrate at center of Mo and physiological electron acceptor $[69,70]$. AO is a severe oxidase that is being not capable to bind NAD but solely with molecular oxygen usage as electron acceptor. The fact that IAA belongs to the plant hormones auxin family proposes a probable physiological role of AO enzymes in biosynthesis of auxin throughout plant early stages development. The characteristics most prominent that differentiate AO from XDH enzymes found to concern binding of substrate at the molybdenum center and physiological electron acceptor binding [71].

In A. thaliana four AA01-AAO4, AO genes were recognized whose products forms the heterodimers, homodimers as well as thus lead to changed respective isoenzymes substrate specificities [72-74]. For AAO1 and AAO2, both efficiently catalyze in vitro indole acetaldehyde oxidation to indole-3-acetic acid. AAO4 in siliques is expressed preferably and catalyzes the benzaldehyde oxidation into benzoic acid and latter being amalgamated into glucosinolates that serve as defense compounds of herbivore [11]. AO enzymes are the firm oxidases that unable to bind NAD+ and solely usage molecular oxygen as an electron acceptor, thus generating hydrogen peroxide [9].AA01 and AAO2 gene products, in seedlings six day old form heterodimers and homodimers, AO isoenzymes that are capable of making indole 3 acetic acid[72]. Arabidopsis mutants with AAO3 deficiency hence by reduced level of ABA are characterized accompanied through excessive loss of water and wilty phenotype, reduced stress tolerance and stunted vegetative growth [74].

AO isoform AAO3 by abscisic aldehyde turns superlative as substrate. Abscisic aldehyde is native precursor of absicisic acid plant hormone that is vital for numerous growing processes as well as for a variety of biotic and abiotic stress responses [75-77]. Another AO isoform known is AO $\delta$ that is required for abscisic aldehyde oxidation producing the abscisic acid phytohormone [8]. For various developmental processes and for various biotic and abiotic stress responses, Abscisic acid is essential for these [77]. Mutant analysis and tissue distribution from the specificity of substrate it could be concluded that Arabidopsis AO3 catalyses the transformation of abscisic aldehyde to ABA (abscisic acid), the final step in ABA-biosynthesis [78,79]. In the IAA over producing mutant sur1, A01 activity is being found five times greater as compared to wild type of Arabidopsis [80]. Thus, for numerous physiological processes, AO is extremely significant in plants including the onset of senescence. Other AO isoenzymes are involved in auxin phytohormones biosynthesis in early plant development stages.

By high preference, the homodime AAO3 is considered for the abscisic aldehyde as substrate [74], that is the ultimate $\mathrm{ABA}$ precursor which is involved in numerous features of plant development and growth, together with maturation of seed, leaf senescence dormancy, and adaptation to diversity of environmental stresses absolutely use the molecular oxygen as electron acceptor. Upon transfer of substrate-derived electrons to molecular oxygen, plant AO generates hydrogen peroxide [9]. Recently, levels of AAO3 protein by ubiquitin reliant degradation have shown to be controlled via $26 \mathrm{~S}$ proteasome to avoid premature senescence through ABA accumulation [81]. This proposes that during the senescence onset, in $\mathrm{AO}$ proteins the synthesis of $\mathrm{ABA}$ also play an acute role that needs a tight control of levels of AO and ABA. From maize, Arabidopsis and tomato, the AO gene has been cloned where four AO cDNAs were seen and mapped physically to dissimilar chromosomes [82,83]. The isoforms of encoded enzyme have comparatively extensive substrate specificity for numerous aldehydes comprising indole-3-acetaldehyde, abscisic aldehyde, benzaldehyde and indole-3-aldehyde. The extensive AO substrate specificity creates it likely that AOs are involved in extra metabolic reactions other than the synthesis of phytohormone. Response of pathogen and reactions detoxification might be good applicants for these additional functions. Therefore, in plants AO enzymes are vital for several physiological processes that need absicisic acid involvement and also maybe of auxins. Because of the ABA 
function in many aspects of plant development and growth and in a range of abiotic stresses adaptation, with reduced levels of $\mathrm{ABA}$ plants deficient in AAO3 are described by more transpiration rate, impaired seed dormancy and reduced stress tolerance [84].

\section{XDH and Its Function}

$\mathrm{XDH}$ is the important key enzyme of purine degradation. XDH needs FAD, Moco, and the two iron sulfur clusters [85]. XDH like all Mo-enzymes, is a functional dimer comprises of two alike subunits. By a molecular mass $300 \mathrm{kDa}$ plant XDH is homodimeric [86] and $\mathrm{XDH}$ was seen also to catalyze ROS substrate independent formation because of an intrinsic NADH oxidase activity. XDH is active as a homodimer of two alike subunits, each one being subdivided in distinct three domains, $\mathrm{N}$ terminal domain for binding two clusters [2Fe-2S], a FAD-binding site domain, and a $\mathrm{C}$ terminal domain necessary for dimerization and Moco binding. Plant XDH displays maximum affinities for hypoxanthine and xanthine as substrate, but it also at much lower rates accepts pterins and purines [87].

XDH each subunit consists of three distinctive domains essential for two [2Fe-2S] clusters binding, FAD and Moco, respectively, while domain essential for dimerization is merged to domain Moco binding. Into distinct three domains, monomer could be subdivided, domain $\mathrm{N}$-terminal for two [2Fe-2S] type clusters binding, a FADbinding site domain, and $\mathrm{C}$ terminal domain that is essential for dimerization and Moco-binding. Electrons resulting upon substrate conversion are nourished in intra molecular electron transmission enzyme chain and go from the center of Mo via clusters [2Fe-2S] to cofactor FAD. Here to form NADH electrons either transferred to NAD, or to molecular oxygen, therefore producing superoxide anions [9] and might, so, into reactive oxygen metabolism have supplementary physiological functions because of increasing XDH activities. At NAD+ tremendously lower concentrations, as alternate electron acceptor molecular oxygen can assist with simultaneous superoxides generation [88]. Plant XDH production of ROS may be of physiological significance because XDH increasing activities and ROS simultaneous production were detected upon interactions of plant-pathogen, natural senescence, drought stress, hypersensitive response and virus infection [89-91].

During senescence oxidative processes comprise enzyme activities increase producing superoxide ions and oxygen radicals. In leaves of pea, activity of XDH was increased sharply in analogous with enzymes related to oxygen and superoxide dismutase [92]. The XDH function is crucial as showed by plants that are deficient in $\mathrm{XDH}$, for plant growth, fertility and senescence [93]. XDH displays strong intrinsic activity of NADH oxidase that is complemented by consumption of oxygen as an electron acceptor and simultaneous superoxide anions formation [88]. It is guessed that this key activity has significance in the abiotic and biotic stresses response. With microbodies XDH could be related and later this was described that peroxisomes in pea leaf have activity of XDH that catabolizes inside the organelles, xanthine to uric acid. In contrast, in nodules of cowpea, XDH immunocytochemistry revealed a cytoplasmic location, and in the Arabidopsis $\mathrm{XDH}$ sequence no targeting signal was found $[94,95]$. In Arabidopsis two genes were founded that are situated in genome side by side, encoding XDH1 and $\mathrm{XDH} 2$ isoenyzmes [90]. Activity of XDH increases when the phytopathogenic fungi Uromyces or Puccinia infect legumes and cereals [96]. Whether this response is aimed at oxidative defence mechanisms it still unknown; however, in pea, XDH activity is strongly correlated with the activity of superoxide dismutase [92].

The fixed nitrogen export and mobilization out of nodule needs the molybdoenzyme XDH activity. Dependent on species of legume, fixed $\mathrm{N}$ is exported as either ureides or amides, that are derived initially from purines oxidative breakdown. In this process, hypoxanthin conversion to xanthine and conversion of the xanthine to uric acid is catalyses by XDH [26]. Onto the activity of XDH, the direct special effects of deficiencies of Mo in nodules of legume could affect on the plants ability to export proficiently reduced $\mathrm{N}$ from nodule. It is poorly understanding that how other and this response related plant defense are interconnected to plant Mo nutrition is understood poorly. With lesser numeral of studies exception, to conclude there is slight straight evidence that in plant Mo levels improvements results in a reduction of disease, that indicates in tomato verticillium wilt fertilization of Mo can increase resistance [31]. Furthermore, to the xanthine and hypoxanthine dependent construction of ROS also with superoxide simultaneous production, activities of NADH oxidase have been revealed for plant XDH [88]. As this activity is highly prominent, this suggests that XDH is an effective superoxide producer in vivo also, and that enzyme could be involved in NADH and NAD cellular regulation balance.

\section{SO and Its Function}

The SO enzyme is significant for sulfite detoxification, i.e. the sulfite oxidation to sulfate and has $90 \mathrm{kDa}$ molecular mass for dimer. In chloroplasts in the course of primary sulphate assimilation, sulphate via sulphite is reduced to organic sulphide that is used for biosynthesis of cysteine [97-99]. In plant kingdom the gene SO is greatly conserved and widespread. As redox center, SO retains only Moco and together with mARC, is the simplest Mo enzyme found in eukaryotes. However, Plant SO enzyme, is peroxisomal enzyme that as electron acceptor uses molecular oxygen and during catalysis forms hydrogen peroxide simultaneously $[7,100,101]$. The latter fact could describe the SO peroxisomal localization since during oxidation of sulfite, excess hydrogen peroxide generated, by catalase may eliminated easily. As sulfite is being sturdy nucleophile that can react with a wide range of cellular components it was supposed that SO possesses function of sulfite detoxifying and is necessary for eliminating surplus sulfite from cell [7,27]. In support of this, [27] found independently that in comparison to plants wild type plants deficient in SO are more susceptible to sulfite high concentrations while overexpressing SO plants are more excess sulfite tolerant. However, in normal situations, in plants the loss of the activity of SO 
is not associated to an apparent phenotype, suggesting that rather than housekeeping metabolic enzyme, SO symbolizes salvage enzyme [102]. Though, it also been described that back to sulphate, sulphite could be oxidized, e.g., when $\mathrm{SO} 2$ gas subjected to plants or, when the isolated chloroplasts were fed with labelled sulphite radioactively. Activity of Sulphite oxidizing was identified in the dark and light $[103,104]$. Therefore, sulphate assimilation would be counteracting by SO, providing that in chloroplast it would be localized. In normal conditions, SO is submitted to be sulfate sulfite cycle part which is highly important for sulfur distribution fine tuning in cell.

The compartmentalization of sulphur assimilation and sulphite oxidation in different organelles allows plants to coregulate these opposing metabolic demands. In chloroplasts oxidation of sulfite was seen to be increaseable by the light and sensitive to photosynthetic electron transport inhibitors and thus due to the reactions that are non-enzymatic was interpreted to be mainly during the electron transport [105]. Though, there exists a new sulfite oxidizing activity that also happens in dark and can be pelleted when isolated chloroplasts are broken. From spinach chloroplasts, latter activity was purified, and it has been found to be connected with the thylakoid membranes $[103,105,106]$. Plant SO known to date amongst eukaryotes, the one that is lacking active redox centres other than the Moco. The association of SOs Moco domains from different sources with Arabidopsis NR and SO shows significant whole homology, pinpointing these enzymes such as members of the common family [98]. Amongst higher plants Plant SO is conserved as evinced by fact that upraised antibodies against Arabidopsis SO identified a dominantly protein band cross reacting of almost $45 \mathrm{kDa}$ in an extensive variety of species belonging to range of both woody herbacious plants.

\section{Mitochondrial Amidoximereductase and Its Function}

mARC (mitochondrial amidoxime reducing component) was exposed as fifth eukaryotic Mo cofactor having enzyme [107]. For Mo-enzymes and Moco biosynthesis, all genomes of eukaryotes well-known to encode the proteins, as well encode two proteins mARC, proposing that the mARC proteins custom an own minor protein family [108]. All mARC eukaryotic proteins comprising the counterparts of the plant, which forecast these proteins mitochondrial localization, are described by $\mathrm{N}$-terminal extensions presence. With average $35 \mathrm{kDa}$ molecular mass and because of fact that as only prosthetic group they bind Moco, mARC protein are the smallest Mo-enzymes identified as yet. It is supposed that in metabolism they show detoxifying role. mARC is the three protein amidoxime reducing chain catalytic partner which consist of also cytochrome ${ }_{b 5}$ reductase and NADH dependent cytochrome ${ }_{b 5}$, that are involved in transfer of electron from NADH to mARC (Figure 3) [109].

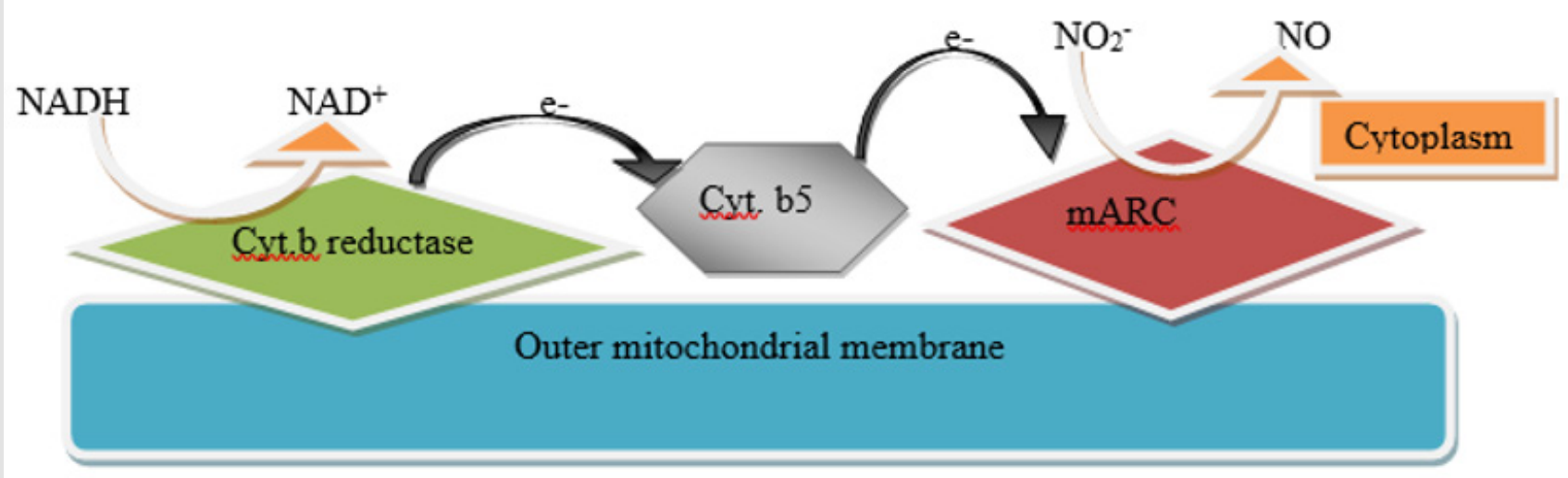

Figure 3: Schematic representation of the mARC-containing enzymatic system, comprising mARC, cytochrome b5 (cyt. b5) and NADH dependent cytochrome b5 reductase.

In contrast, entirely other Mo enzymes, mARC eukaryotic proteins not show on their own the enzymatic activity but need other proteins alike $\mathrm{NADH}$, cytochrome ${ }_{\mathrm{b} 5}$ reductase and cytochrome ${ }_{\mathrm{b} 5}$ as electron donors and electron transmitters, respectively thus forming the mARC enzyme complex [110].The two other proteins, $\mathrm{CY}_{\mathrm{B} 5} \mathrm{R}$ (cytochrome ${ }_{\mathrm{b} 5}$ reductase) and $\mathrm{CY}_{\mathrm{B} 5}$ (cytochrome ${ }_{\mathrm{b} 5}$ ), from NADH to terminal oxidoreductase, mARC catalyze transfer of electron [110]. NO (nitric oxide) from nitrite can be generated by mARC when forming a chain of electron transfer with NADH, NA$\mathrm{DH}$-dependent cytochrome ${ }_{b 5}$ reductase and cytochrome ${ }_{b 5}$. When $\mathrm{pH}$ decreased from 7.5 to 6.5 , the NO formation rate rises three- fold. [111] conducted the experiment to determine if reduction of nitrite is catalyzed through Mo in mARC-1 active site, they mutated Cys-273 (putative active site cysteine residue), known to coordinate Mo binding. N-hydroxylated nucleobases and HAPR (N-hydroxy-adenosine) or nucleosides as HAP (N-hydroxylaminopurine) may be endogenously generated in course of metabolism of cell by cytochrome P450, biosynthesis of deviating nucleotide or oxidative stress. For eukaryotic and prokaryotic cells these compounds have revealed to be the toxic and mutagenic. For replication of DNA dependability, it is thus of key significance that organisms to eradicate such non canonical base correspondents from DNA precursor tarns 
display operative mechanisms. In vitro, mARC1 and mARC2 have revealed to be proficient of reducing $\mathrm{N}$ nucleoside analogs and hydroxylated base analogs to resultant canonical nucleosides and nucleobases on reconstruction with electron transport proteins $\mathrm{CY}_{\mathrm{B} 5}$ and $\mathrm{NADH}-\mathrm{CY}_{\mathrm{B} 5} \mathrm{R}$ [112]. As a sole prosthetic group mARC protein bind Moco [110]. mARC proteins belong to the SO-family most likely, but final confirmation needs to be provided [Figure 3].

\section{Role of Molybdenum in Abiotic Stress Mediation}

Mo have significant roles in resisting numerous environmental stresses, such as drought, salt stress and cold [113-118]. Amongst the abiotic stresses low temperature is the most important affecting plant growth, development, distribution and production all over the world. Under cold stress in the winter wheat, Mo was having progressive impacts on drought stress, rates and products of photosynthesis. Through the antioxidative enzymes escalating activities Mo also boosted the turf grass chilling resistance [20,118-120] revealed that Mo reduced Cd concentration under the Cd stress. Moreover, as a result of Mo excess or deficiency it has been described that the biomass, product quality and seed yield all deteriorated [121]. Low temperatures can be tolerated by some plants in a process that is called as cold acclimation, this happens when plants are wide-open to non-freezing low temperature $\left(4^{\circ} \mathrm{C}\right)$ $[122,123]$. Throughout the process of acclimation, various alterations happen such as osmoprotectants accumulation alike amines, soluble sugar, and compatible solutes such as proline, polyols, and betaine, through activation of low temperature signal pathways of transduction that ultimately lead to transformed gene expression and membrane stability to provide tolerance at all levels [124-126].

In Arabidopsis intensive studies on cold response gene expression led to the DREB1/CBF transcription factors identification that has a crucial role in plants during freezing and cold acclimation stress tolerance [127]. In the cold promoters and genes responsive for dehydration, these transcription factors also bind to sequences of specific regulatory. These sequences are elements responsive for dehydration and C-repeat. These both sequences have the highly 5-bp conserved sequence of CCGAC that has the ability to transcription regulation in drought, salinity and temperature [128]. Therefore, CBF induces the COR genes expression and in plant cold tolerance improvement these genes have an important crucial role. $[129,130]$ reported the Mo optimistic influence on the improvement of cold tolerance in the cauliflower without acclimation.

Earlier study showed that under cold stress, deficiency of Mo inhibits the chlorophyll biosynthesis and leads to chlorophyll decrease in cultivars of winter wheat [131] and through Mo application showed the positive effect on stomatal conductance, photosynthetic rate and decreased transpiration rate in winter wheat under stress of low temperature[118,132].On the other hand, in chickpea excess Mo reduced the biomass, lessened the produce quality and yield of seed yield [121,115] and [133]have stated that for wheat gene expression may be altered not just by decreased in temperature $\left({ }^{\circ} \mathrm{C}\right)$, but subsequent disclosure to certain chemicals that were used for priming of seed e.g. Mo, that can upsurge the expression of CBF. Moreover, this study also indicated that to tolerate decrease in temperature these chemicals improved the ability of plants due to the ABA biosynthesis regulation via $\mathrm{AO}$, and ABA is takes part in mediating of COR (Cold regulated) expression of genes. In the meantime, [115] have described that the activity of $\mathrm{AO}$, IAA and ABA content increased in wheat leaves that were treated with Mo. It also been earlier suggested that in frost damage amelioration, Mo can be involved [133,134].

Worldwide drought stress as a main environmental stress is well known that limits the crop plants development, yield and growth, and can generate a series of biochemical and physiological plants responses [135]. The main biochemical and physiological characteristics not just associated to photosynthesis inhibition, decline in transpiration, decline in chlorophyll content and stomata closure but are involved also in ability of osmotic adjustment and antioxidant that are significant ways to increase resistance of plant to drought capacity [136]. Numerous studies have presented that drought stress may result in more active oxygen species production such as hydroxyl radicals, superoxides and superoxide radical [137], that results membrane damage and cell death [138-140] reported that the antioxidant enzymes activities such as superoxide dismutase, ascorbate peroxidase, peroxidase, catalase, and nonenzymatic antioxidants content like ascorbic acid, carotenoid, reduced glutathione, were increased significantly and decreased malonaldehyde contents through application of Mo in drought stress, suggesting that application of Mo improved the scavenging ability of species of active oxygen. Through increasing the antioxidant enzymes activities active oxygen species are scavenged by plants such as CAT (catalase), SOD (superoxide dismutase), APX (ascorbate peroxidase) and POD (peroxidase) or through enhancing non-enzymatic antioxidants levels such as, GSH (glutathione), AsA (ascorbic acid) and CAR (carotenoid)[141,142].

Furthermore, in plants to resist stress of drought osmotic adjustment also is significant way. The substances that help in osmoregulation such as proline, soluble proteins and soluble sugar also show important roles in osmotic equilibrium maintenance and under deficiency water the integrity of membranes [143]. The wheat drought tolerance might be improved through the application of Mo by enhancing utilization capability of water, antioxidative defense abilities and osmotic adjustment. It is described also that overexpression sulfurase gene Mo cofactor confers drought tolerance in tobacco, soybean, cotton and maize [144]. Environmental adversative conditions comprising soil salinity, heavy metal contamination and water stress can affect intensely on plants nitrogen assimilation, this rises from the stress effect on nitrogenase and nitrate reductase enzymes activity. [116] have showed that Chinese cabbage fresh weight increased significantly by the Mo application under the salt stress. They also indicated that under salt stress the nonenzymatic antioxidants 
contents and antioxidant enzyme activities were extraordinarily enhanced by application of Mo. By Mo application accumulating products of the Osmotic adjustment were also increased dramatically under salt stress. Furthermore, the ratios $\mathrm{Na}+\mathrm{K}+$ were increased intensely and with the Mo application rates were correlated positively. Hence, we can see that the Mo application tolerance to salinity was improved by the osmotic stress tolerance and increasing eliminating active oxygen ability. [145] studied the Mo deficiency stress effect on viability, seedling growth and seed germination of wheat and described that deficiency of Mo results in necrotic spots on wheat leaves and wrinkled and poor seeds. [67] also reported a remarkable reduction in activity of nitrate reductase and metabolism of nitrogen under deficiency of Mo [146-150].

\section{Concluding Remarks and Future Prospects}

Molybdenum nutrition for healthy growth and development of plant is key essential where it is being obligatory as a metal that is catalytically active in catalysis of enzymes that accomplishes functional roles in plants enzyme systems and known to participate in numerous redox reactions. Five Mo-enzymes in plants are identified to this end: $\mathrm{NR}, \mathrm{AO} \mathrm{SO}, \mathrm{XDH}$, and mARC that catalyze key significant reactions in nitrogen assimilation, phytohormone synthesis, sulfite detoxification and purine degradation. NR catalyses the nitrate reduction into nitrite and SO oxidizes sulphite that toxic into sulphate. In the nitrogen metabolism for degradation of purine XDH is needed and can produce ROS while AO is involved in the ABA synthesis, glucosinolates and auxin. mARC are the smallest Mo enzymes identified as yet showing the detoxifying role. Current years have conveyed prompt improvement in our understanding of Mo role and function in plants. Evidently, research focuses on studying the Mo enzymes structure-function relationships. However, a still large number of unresolved questions is there that requisite to be answered.

a) What additional metabolic reactions by $\mathrm{AO}$ family member are catalyzed?

b) The question during senescence what exact role XDH plays in metabolism of activated oxygen, remains to be answered?

c) Why in peroxisomes the SO is localalized? And what SO plays the exact role?

d) In details, how molybdate transporter is being organized?

e) For biosynthesis of Moco, how the multi-enzyme complex organized? What is Moco insertion mechanism into the apoenzymes? To meet the cell changing demands for Moco how is Moco biosynthesis has been regulated?

f) What factors effect tungsten incorporation instead of the Mo in some enzymes?

g) What key roles $\mathrm{CnX} 4$ have is not so much clear?
Future research Mo enzymes field is likely to emphasis on detailed mechanistic of cofactors functions, biosynthesis of cofactor and their allocation in specific enzymes. Considerable further research is necessary to ascertain that how the element in the future may be used to develop growing areas where molybdate soil profiles limit the growth of plant. The years coming, into these will bring insight and perhaps Mo novel aspects within the physiological and metabolic cell network.

\section{Acknowledgement}

None.

\section{Conflict of Interest}

No conflict of interest.

\section{References}

1. Hille R (2002) Molybdenum and tungsten in biology, Trends Biochem Sci 27: 360-367.

2. Stiefel EI (2002) The biogeochemistry of molybdenum and tungsten. Met Ions Biol Syst 39: 1-29.

3. Turnlund JR (2002) Molybdenum metabolism and requirements in humans. Met Ions Biol Syst 39: 727-739.

4. Andreini C, Bertini I, Cavallaro G, Holliday GL, Thornton JM (2008) Metal ions in biological catalysis: from enzyme databases to general principles, JBIC 13: 1205-1218.

5. Bittner F, Oreb M, Mendel RR (2001) ABA3 is a molybdenum cofactor sulfurase required for activation of aldehyde oxidase and xanthine dehydrogenase in Arabidopsis thaliana. Journal of Biological Chemistry 276: 40381-40384.

6. Kruse T, Gehl C, Geisler M, Lehrke M, Ringel P, et al. (2010) Identification and biochemical characterization of molybdenum cofactor-binding proteins from Arabidopsis thaliana. Journal of Biological Chemistry 285: 6623-6635.

7. Nowak K, Luniak N, Witt C, Wustefeld Y, Wachter A, et al. (2004) Peroxisomal localization of sulfite oxidase separates it from chloroplastbased sulfur assimilation. Plant Cell Physiol 45: 1889-1894.

8. Seo M, Koiwai H, Akaba S, Komano T, Oritani T, et al. (2000) Abscisic aldehyde oxidase in leaves of Arabidopsis thaliana. Plant J 23: 481-488.

9. Yesbergenova Z, Yang G, Oron E, Soffer D, Fluhr R, et al. (2005) The plant Mo-hydroxylases aldehyde oxidase and xanthine dehydrogenase have distinct reactive oxygen species signatures and are induced by drought and abscisic acid, Plant J 42: 862-876.

10. Nakagawa A, Sakamoto S, Takahashi M, Morikawa H, Sakamoto A (2007) The RNAi-mediated silencing of xanthine dehydrogenase impairs growth and fertility and accelerates leaf senescence in transgenic Arabidopsis plants. Plant Cell Physiol 48: 1484-1495.

11. Ibdah M, Chen YT, Wilkerson CG, Pichersky E (2009) An aldehyde oxidase in developing seeds of Arabidopsis converts benzaldehyde to benzoic acid. Plant Physiol 150: 416-423.

12. Zhang Y, Rump S, Gladyshev VN (2011) Comparative genomics and evolution of molybdenum utilization. Coord Chem Rev 255: 1206-1217.

13. Schwarz, Mendel G, Ribbe RR, MW (2009) Molybdenum cofactors, enzymes and pathways. Nature 460: 839-847.

14. Hille R (1996) The mononuclear molybdenum enzymes, Chem Rev 96: 2757-2816.

15. Zhang Y, Gladyshev VN (2008) Molybdoproteomes and evolution of molybdenum utilization. J Mol Biol 379: 881-899. 
16. Mengel K, Kirkby EA (2001) Principles of Plant Nutrition ( $5^{\text {th }}$ Edn.) Kluwer Academic Publishers, Dordrecht, The Netherlands, pp. 480.

17. Fido RJ, Gundry CS, Hewitt EJ, Notton BA (1977) Ultrastructural features of molybdenum deficiency and whiptail in cauliflower leaves: effects of nitrogen source and tungsten substitution for molybdenum. Aust J Plant Physiol 4: 675-689.

18. Unkles SE, WangR, WangY, Glass ADM, Crawford NM, et al. (2004) Nitrate reductase activity is required for nitrate uptake into fungal but not plant cells. Journal of Biological Chemistry 279: 28182-28196.

19. Witt HH, Jungk A (1977) Beurteilung der Molybdanversorgung von Pflanzen mit Hilfe der Mo-induzierbaren Nitratreduktase-Aktinitat. Zeitschrift für Pflanzenernahrung und Bodenkunde 140: 209-222.

20. Yaneva I, Mack G, Vunkova Radeva R, Tischner R (1996) Changes in nitrate reductase activity and the protective effect of molybdenum during cold stress in winter wheat grown on acid soil. J Plant Physiol 149(1/2): 211-216.

21. Williams CMJ, Maier NA, Bartlett L (2004) Effect of molybdenum foliar sprays on yield, berry size, seed formation, and petiolar nutrient composition of 'Merlot' grapevines. Journal of Plant Nutrition 27: 18911916.

22. Tomatsu H, Takano J, Takahashi H, Watanabe Takahashi A, Shibagaki N, et al. (2007) An Arabidopsis thaliana high affinity molybdate transporter required for efficient uptake of molybdate from soil. Proc Natl Acad Sci USA 104: 18807-18812.

23. Baxter I, Muthukumar B, Park HC, Buchner P, Lahner B, et al. (2008) Variation in molybdenum content across broadly distributed populations of Arabidopsis thaliana is controlled by a mitochondrial molybdenum transporter (MOT1). PLoS Genet 4: e1000004

24. Gasber A, Klaumann A, Trentmann O, Trampczynska A, Clemens S, et al. (2011) Identification of an Arabidopsis solute carrier critical for intracellular transport and interorgan allocation of molybdate. Plant Biol (in press).

25. Muller AJ, Mendel RR (1989) Biochemical and somatic cell genetics of nitrate reductase in Nicotiana. In Wray JL, Kinghorn JR (Eds.)., Molecular and genetic aspects of nitrate assimilation. Oxford University Press, Oxford, UK, pp. 166-185

26. Mendel RR, Haensch R (2002) Molybdoenzymes and molybdenum cofactor in plants. Journal of Experimental Botany 53: 1689-1698.

27. Lang C, Popko J, Wirtz M, Hell R, Herschbach C, et al. (2007) Sulphite oxidase as key enzyme for protecting plants against sulphur dioxide. Plant Cell Environ 30: 447-455.

28. Seo M, Koiwai H, Akaba S, Komano T, Oritani T, et al. (2000a) Abscisic aldehyde oxidase in leaves of Arabidopsis thaliana. Plant J 23: 481-488.

29. Seo M, Peeters AJ, Koiwai H, Oritani T, Marion Poll A, et al. (2000b) The Arabidopsis aldehyde oxidase 3 (AAO3) gene product catalyzes the final step in abscisic acid biosynthesis in leaves. Proc Natl Acad Sci USA 97:12908-12913.

30. Xiong L, Ishitani M, Lee H, Zhu JK (2001) The arabidopsis los5/aba3 locus encodes a molybdenum cofactor sulfurase and modulates cold stress- and osmotic stress-responsive gene expression. Plant Cell 13: 2063-2083

31. Graham RD, Stangoulis JRC (2005) Molybdenum and disease. In Dantoff L, Elmer W, Huber D, (Eds.), Mineral nutrition and plant diseases. St Paul, APS Press, MN.

32. Vieira RF, Cardoso EJBN, Vieira C, Cassini STA (1998) Foliar application of molybdenum in common beans. I. Nitrogenase and reductase activities in a soil of high fertility. J Plant Nutr 21: 169-180.

33. Mendel RR (2005) Molybdenum: biological activity and metabolism. Dalton Transactions: 3404-3409.

34. Kaiser BN, Gridley KL, Brady JN, Phillips T, Tyerman SD (2005) The role of molybdenum in agricultural plant production. Ann Bot 96: 745-754.
35. Smith KS, Balistrieri LS, Smith SM, Severson RC (1997) Distribution and mobility of molybdenum in the terrestrial environment U.C. Gupta (Eds.), Molybdenum in Agriculture, Cambridge University Press, Cambridge, UK, p. 23-46.

36. Micó C, Li HF, Zhao FJ, Mc Grath SP (2008) Use of Co speciation and soil properties to explain variation in Co toxicity to root growth of barley (Hordeum vulgare L.) in different soils Environmental Pollution 156: 883-890.

37. Li HF, Gray C, Micó C, Zhao FJ, Mc Grath SP (2009) Phytotoxicity and bioavailability of cobalt to plants in a range of soils Chemosphere 75 979-986.

38. Kevresan S, Petrovic N, Popovic M, Kandrac J (2001) Nitrogen and protein metabolism in young pea plants as affected by different concentrations of nickel, cadmium, lead, and molybdenum Journal of Plant Nutrition 24: 1633-1644.

39. Hale KL, Mc Grath SP, Lombi E, Stack SM, Terry N, et al. (2001) Molybdenum sequestration in Brassica species. A role for anthocyanins? Plant Physiology 126: 1391-1402.

40. Zhao FJ, Rooney CP, Zhang H, Mc Grath SP (2006) Comparison of soil solution speciation and diffusive gradients in thin-films measurement as an indicator of copper bioavailability to plants Environmental Toxicology and Chemistry 25: 733-742.

41. Gupta UC (1997) Soil and plant factors affecting molybdenum uptake by plants U.C. Gupta (Eds.)., Molybdenum in Agriculture, Cambridge University Press, Cambridge, UK, p. 71-91.

42. Sakihama, Nakamura Y, Yamasaki S (2002) Nitric oxide production mediated by nitrate reductase in the green alga Chlamydomonas reinhardtii: an alternative NO production pathway in photosynthetic organisms Plant Cell Physiol 43: 290-297.

43. Li HF, Kundu TK, Zweier JL (2009) Characterization of the magnitude and mechanism of aldehyde oxidase-mediated nitric oxide production from nitrite. J Biol Chem 284: 33850-33858.

44. Gupta KJ, Igamberdiev AU, Manjunatha G, Segu S, Moran JF, et al. (2011) The emerging roles of nitric oxide (NO) in plant mitochondria. Plant Sci 181: 520-526S.

45. Wang J, Sparacino Watkins C, Kim Shapiro D, Gladwin M (2015) Sulfite oxidase catalyzes single-electron transfer at molybdenum domain to reduce nitrite to nitric oxide Antioxid. Redox Signal 23: 283-294.

46. Sparacino Watkins CE, Tejero J, Sun B, Gauthier MC, John Thomas, et al. (2014) Nitrite reductase and nitric-oxide synthase activity of the mitochondrial molybdopterin enzymes mARC1 and mARC2. J Biol Chem 289: 10345-10358.

47. Chamizo Ampudia A, Galvan, Fernandez E, Llamas A (2013) Characterization of Chlamydomonas 102 and 104 mutants reveals intermolecular complementation in the molybdenum cofactor protein CNX1E Protist, 164: 116-128.

48. Corpas FJ, Palma JM, Del Rio LA, Barroso JB (2009) Evidence supporting the existence of L-arginine-dependent nitric oxide synthase activity in plants. New Phytol 184: 9-14.

49. Bittner F, Mendel RR (2010) Cell biology of molybdenum. Plant Cell Monogr 17:119-146.

50. Campbell WH, Kinghorn KR (1990) Functional domains of assimilatory nitrate reductases and nitrite reductases Trends Biochem Sci 15: 315319.

51. Kaiser WM, Huber SC (2001) Post-translational regulation of nitrate reductase: mechanism, physiological relevance and environmental triggers. J Exp Bot 52: 1981-1989.

52. Crawford NM, Forde BG (2002) Molecular and developmental biology of inorganic nitrogen nutrition. In Somerville C, Meyerowitz E, (Eds.), The Arabidopsis book (in press).

53. Campbell WH (1999) Nitrate reductase structure, function, and regulation. Bridging the gap between biochemistry and physiology. In 
Jones RL, Bohnert HJ, Walbot V, (Eds.), Annual Review of Plant Physiology and Plant Molecular Biology 50: 277-303.

54. Scheible WR, Gonzalez Fontes A, Morcuende R, Lauerer M, Geiger M, et al. (1997) Tobacco mutants with a decreased number of functional nia genes compensate by modifying the diurnal regulation of.

55. Forde BG (2002) The role of long-distance signalling in plant responses to nitrate and other nutrients. Journal of Experimental Botany 53: 39-43.

56. HänschR, Fessel DG, Witt C, Hesberg C, Hoffmann G, et al. (2001) Tobacco plants that lack expression of functional nitrate reductase in roots show changes in growth rates and metabolite accumulation. Journal of Experimental Botany 52: 1251-1258.

57. Forde BG (2000) Nitrate transporters in plants: structure, function and regulation. Biochimica et Biophysica Acta 1465: 219-235.

58. Zhang H, Forde BG (2000) Regulation of Arabidopsis root development by nitrate availability. Journal of Experimental Botany 51: 51-59.

59. Vanin AF, Svistunenko DA, Mikoyan VD, Serezhenkov VA, Fryer MJ, et al. (2004) Endogenous superoxide production and the Nitrite/Nitrate ratio control the concentration of bioavailable free Nitric oxide in leaves, J. Biol. Chem 279: 24100-24107.

60. Hofmann M (2009) Density functional theory study of model complexes for the revised nitrate reductase active site in Desulfovibrio desulfuricans NapA. J Biol Inorg Chem 14: 1023-1035.

61. Silaghi-Dumitrescu R (2004) Heme ferrous-hydroperoxo adducts: some theoretical considerations, Arch. Biochem. Biophys 424: 137-140.

62. Nussaume L, Vincentz M, Meyer C, Boutin JP, Caboche M (1995) Posttranscriptional regulation of nitrate reductase by light is abolished by an N-terminal deletion, Plant Cell 7: 611-621.

63. Campbell WH (2001) Structure and function of eukaryotic NAD(P)H nitrate reductase. Cell Mol Life Sci 58: 194-204.

64. Byrne RS, Hansch R, Mendel RR, Hille R (2009) Oxidative half-reaction of Arabidopsis thaliana sulfite oxidase: generation of superoxide by a peroxisomal enzyme. J Biol Chem 284: 35479-35484.

65. Yamasaki H, Sakihama Y (2000) Simultaneous production of nitric oxide and peroxynitrite by plant nitrate reductase: in vitro evidence for the NR-dependent formation of active nitrogen species. FEBS Lett 468: 89 92.

66. Wang P, Du Y, Song CP (2011) Phosphorylation by MPK6: a conserved transcriptional modification mediates nitrate reductase activation and NO production? Plant Signal Behav (in press).

67. Yaneva IA, Baydanova VD, Vunkova Radeva RV (2000) Nitrate reductase activation state in leaves of molybdenum-deficient winter wheat. Journal of Plant Physiology 157: 495-501.

68. Zarepour M, Simon K, Wilch M, Nielaender U, Koshiba T, et al. (2012) Identification of superoxide production by Arabidopsis thaliana aldehyde oxidases AAO1 and AA03. Plant Mol Biol 80: 659-671.

69. KoshibaT, Saito E, Ono N, Yamamonto N, Sato M (1996) Purification and properties of flavin- and molybdenum containing aldehyde oxidase from coleoptiles of maize. Plant Physiology 110: 781-789.

70. Rodriguez-Trelles F, Tarrio R, Ayala FJ (2003) Convergent neofunctionalization by positive Darwinian selection after ancient recurrent duplications of the xanthine dehydrogenase gene. Proc Natl Acad Sci USA 100: 13413-13417

71. Hille R, Nishino T, Bittner F (2005) Molybdenum enzymes in higher organisms. Coord Chem Rev 255: 1179-1205.

72. Akaba S, Seo M, Dohmae N, Takio K, Sekimoto H, Kamiya Y, et al.(1999) Production of homoand hetero-dimeric isozymes from two aldehyde oxidase genes of Arabidopsis thaliana. J Biochem (Tokyo) 126: 395-401.

73. Koiwai H, Akaba S, Seo M, Komano T, Koshiba T (2000) Functional expression of two Arabidopsis aldehyde oxidases in the yeast Pichia pastoris. J Biochem 127: 659-664.
74. Seo M, Peeters AJ, Koiwai H, Oritani T, Marion-Poll A, et al. (2000c) The Arabidopsis aldehyde oxidase 3 (AAO3) gene product catalyses the final step in abscisic acid biosynthesis in leaves. Proceedings of the National Academy of Sciences, USA 97: 12908-12913.

75. Seo M, Koshiba T (2002) The complex regulation of ABA biosynthesis in plants. Trends in Plant Science 7:41-48.

76. Mauch Mani B, Mauch F (2005) The role of abscisic acid in plantpathogen interactions. Current Opinion in Plant Biology 8: 409-414.

77. Verslues PE, Zhu JK (2005) Before and beyond ABA: upstream sensing and internal signals that determine ABA accumulation and response under abiotic stress. Biochem Soc Trans 33: 375-379.

78. Zeevaart JAD (1999) Abscisic acid metabolism and its regulation. In: Hooykaas PJJ, Hall MA, Libbenga KR, eds. Biochemistry and molecular biology of plant hormones. Amsterdam: Elsevier Science: 189-207.

79. Milborrow BV (2001) The pathway of biosynthesis of abscisic acid in vascular plants: a review of the present state of knowledge of ABA biosynthesis. Journal of Experimental Botany 52: 1145-1164.

80. Seo M, Akaba S, Oritani T, Delarue M, Bellini C, et al. (1998) Higher activity of an aldehyde oxidase in the auxin-overproducing superroot1 mutant of Arabidopsis thaliana. Plant Physiology 116: 687-693.

81. Raab S, Drechsel G, Zarepour M, Hartung W, Koshiba T, et al. (2009) Identification of a novel E3 ubiquitin ligase that is required for suppression of premature senescence in Arabidopsis. Plant J 59: 39-51.

82. Ori N, Eshed Y, Pinto P, Paran I, Zamir D, et al. (1997) TA01, A representative of the molybdenum cofactor containing hydroxylases from tomato. Journal of Biological Chemistry 272: 1019-1025.

83. Sekimoto H, Seo M, Kawakami N, Komano T, Desloire S, et al. (1998) Molecular cloning and characterization of aldehyde oxidases in Arabidopsis thaliana. Plant Cell Physiology 39: 433-442.

84. Seo M, Koshiba T (2011) Transport of ABA from the site of biosynthesis to the site of action. J Plant Res 124: 501-507.

85. Hille R, Nishino T, Bittner F (2011) Molybdenum enzymes in higher organisms. Coord Chem Rev 255: 1179-1205.

86. Montalbini P (1998) Purification and some properties of xanthine dehydrogenase from wheat leaves. Plant Science 134: 89-102.

87. Corpas FJ, Palma JM, Sandalio LM, Valderrama R, Barroso JB, et al. (2008) Peroxisomal xanthine oxidoreductase: characterizationof the enzyme from pea (Pisum sativum L.) leaves. J Plant Physiol 165: 1319-1330.

88. Zarepour M, Kaspari K, Stagge S, Retmeiere R, Mendel RR, et al. (2010) Xanthine dehydrogenase AtXDH1 from Arabidopsis thaliana is a potent producer of superoxide anions via its NADH oxidase activity. Plant Mol Biol 72: 301-310

89. Montalbini P, Della Torre G (1996) Evidence of a two-fold mechanism responsible for the inhibition by allopurinol of the hypersensitive response induced in tobacco by tobacco necrosis virus. Phys Mol Plant Pathol 48: 273-287.

90. Hesberg C, Hansch R, Mendel RR, Bittner F (2004) Tandem orientation of duplicated xanthine dehydrogenase genes from Arabidopsis thaliana: differential gene expression and enzyme activities. J Biol Chem 279: $13547-13554$

91. Silvestri S, Murphy AM, Buonaurio R, Carr JP (2008) Allopurinol, an inhibitor of purine catabolism, enhances susceptibility of tobacco to Tobacco mosaic virus. Virus Res 137: 257-260.

92. Pastori GM, Rio LA (1997) Natural senescence of pea leaves: An activated oxygen-mediated function for peroxisomes. Plant Physiol 113: 412-418.

93. Brychkova G, Alikulov Z, Fluhr R, Sagi M (2008) A critical role for ureides in dark and senescence-induced purine remobilization is unmasked in the Atxdh1 Arabidopsis mutant. Plant J 54: 496-509.

94. Datta DB, Triplett EW, Newcomb EH (1991) Localization of xanthine dehydrogenase in cowpea root nodules: implications for the interaction 
between cellular compartments during ureide biogenesis. Proc Nat Acad Sci USA 88: 4700-4702.

95. Corpas FJ, Colina C, Sanchez Rasero F, Rio LA (1997) A role of leaf peroxisomes in the catabolism of purines. Journal of Plant Physiology 151: $246-250$.

96. Montalbini P (1992) Inhibition of hypersensitive response by allopurinol applied to the host in the incompatible relationship between Phaseolus vulgaris and Uromyces phaseoli. J Phytopathol 134: 218-228.

97. Leustek T, Saito K (1999) Sulfate transport and assimilation in plants. Plant Physiology 120: 637-644.

98. Eilers T, Schwarz G, Brinkmann H, Witt C, Richter T, et al. (2001) Identification and biochemical characterization of Arabidopsis thaliana sulfite oxidase. A new player in plant sulfur metabolism. J Biol Chem 276: 46989-46994.

99. Saito K (2004) Sulfur assimilatory metabolism. The long and smelling road. Plant Physiology 136: 2443-2450.

100. Hansch R, Lang C, Riebeseel E, Lindigkeit R, Gessler A (2006) Plant sulfite oxidase as novel producer of H202: combination of enzyme catalysis with a subsequent non-enzymatic reaction step. Journal of Biological Chemistry 281: 6884-6888.

101. Byrne RS, Hansch R, Mendel RR, Hille R (2009) Oxidative half-reaction of Arabidopsis thaliana sulfite oxidase: generation of superoxide by a peroxisomal enzyme. J Biol Chem 284: 35479-35484.

102. Hansch R, Lang C, Rennenberg H, Mendel RR (2007) Significance of plant sulfite oxidase. Plant Biol 9: 589-595.

103. Jolivet P, Bergeron E, Zimierski A, Meunier JC (1995a) Metabolism of elemental sulphur and oxidation of sulphite by wheat and spinach chloroplasts. Phytochemistry 38: 9-14

104. Heber U, Huve K (1998) Action of SO2 on plants and metabolic detoxification of $\mathrm{SO}_{2}$. International Review of Cytology 177: 255-286.

105. Dittrich APM, Pfanz H, Heger U (1992) Oxidation and reduction of sulfite by chloroplasts and formationof sulfite addition compounds. Plant Physiol 98: 738-744.

106. Rennenberg H, Herschbach C (1996) Response of plants to atmospheric sulfur. In: Plant Response to Air Polution. Yunus M, Iqbal M, (Eds.), John Wiley and Sons, New York, USA.

107. Klein JM, Busch JD, Potting C, Baker MJ, Langer T, et al. (2012) The mitochondrial amidoxime-reducing component (mARC1) is a novel signal-anchored protein of the outer mitochondrial membrane J Biol Chem 287(51): 42795-42803.

108. Wahl B, Reichmann D, Niks D, Krompholz N, Havemeyer A, et al (2010) Biochemical and spectroscopic characterization of the human mitochondrial amidoxime reducing components hmARC-1 and hmARC-2 suggests the existence of a new molybdenum-enzyme family in eukaryotes. J Biol Chem 285: 37847-37859.

109. Plitzko B, Ott G, Reichmann D, Henderson CJ, Wolf CR, et al. (2013) Cytochrome. J Biol Chem 288: 20228

110. Havemeyer A, Bittner F, Wollers S, Mendel R, Kunze T, et al. (2006) Identification of the missing component in the mitochondrial benzamidoxime prodrug-converting system as a novel molybdenum enzyme. J. Biol. Chem. 281: 34796-34802.

111. Courtney E, Sparacino Watkins, Jesús Tejero, Bin Sun, Marc C Gauthier, et al. (2014) Nitrite Reductase and Nitric-oxide Synthase Activity of the Mitochondrial Molybdopterin Enzymes mARC1 and mARC2. J Biol Chem 289(15): 10345-10358.

112. Birte Plitzko, Antje Havemeyer, Thomas Kunze, Bernd Clement (2015) The Pivotal Role of the Mitochondrial Amidoxime Reducing Component 2 in Protecting Human Cells Against Apoptotic Effects of the Base Analog N6-Hydroxylaminopurine April 17, 2015 The Journal of Biological Chemistry 290: 10126-10135.

113. Katerji N, Van Hoorn JW, Hamdy A, Mastrorilli M (2000) Salt tolerance classification of crops according to soil salinity and to water stress an index. Agric. Water Manage 43: 99-109.

114. El Samad HA, El Komy HM, Shaddad M, Hetta AM (2005) Effect of molybdenum on nitrogenase and nitrate reductase activities of wheat inoculated with azospirillum brasilense grown under drought stress. Gen Appl Plant Physiol 31: 43-54.

115. Sun X, Hu C, Tan Q Liu J, Liu H (2009) Effects of molybdenum on expression of cold-responsive genes in abscisic acid (ABA)-dependent and ABA-independent pathways in winter wheat under lowtemperature stress. Ann. Bot 104: 345-e356.

116. Zhang M, Hu C, Zhao X, Tan Q Sun X, et al. (2012) Molybdenum improves antioxidant and osmotic-adjustment ability against salt stress in Chinese cabbage (Brassica campestris L. ssp. Pekinensis). Plant Soil 355: 375-383.

117. Al Issawi M, Rihan HZ, Woldie WA, Burchett S, Fuller MP (2013) Exogenous application of molybdenum affects the expression of CBF14 and the development of frost tolerance in wheat. Plant Physiol. Biochem 63: 77-81.

118. Ghafarian, AH, Zarghami R, Zand B, Bayat V (2013) Wheat performance as affected by foliar application of molybdenum (Mo) under drought stress condition. Inter J Agro Plant Prod 4: 3050-e3056.

119. Yu M, Cheng YJ, Xiao HD, Wang HF, Wang F, et al. (2005) Influences of boron and molybdenum on active oxygen species in turfgrass seashore Paspalum under low temperature. Acta Agron Sin 6: 755-759.

120. Xiao YH, He JM, Cheng Y, Zhu YM, Huang LY (2009) Effects of molybdenum on cadmium content and physiological indices of Chinese white cabbage under cadmium stress. J Anhui Agri Sci 9: 3909-3910.

121. Nautiyal N, Chatterjee C (2004) Molybdenum stress-induced changes in growth and yield of chickpea. J Plant Nutr 1: 173-181.

122. Fowler DB (2007) Cold hardy wheat, in: Proceedings Saskatchewan Soil Conservation Association 19th Annual Conference: pp. 33-38.

123. Thomashow MF (1999) Plant cold acclimation: freezing tolerance genes and regulatory mechanisms. Annu Rev Plant Physiol Plant Mol Biol50(1): 571-599.

124. Allard F, Houde M, Korol M, Ivanov NP, Sarhan (1998) Betaine improves freezing tolerance in wheat, Plant and Cell Physiology 39: 1194-1202.

125. Uemura M, Warren G, Steponkus PL (2003) Freezing sensitivity in the sfr 4 mutant of Arabidopsis is due to low sugar content and is manifested by loss of osmotic responsiveness. Plant Physiology 131: 1800-1807.

126. Thomashow MF (2010) Molecular basis of plant cold acclimation: insights gained from studying the CBF cold response pathway, Plant Physiology 154: 571-577.

127. Gilmour SJ, Zarka DG, Stockinger EJ, Salazar MP, Houghton JM, et al (1998) Low temperature regulation of the Arabidopsis CBF family of AP2 transcriptional activators as an early step in cold-induced COR gene expression. Plant J 16(4): 433-442.

128. Gao JP, Chao DY, Lin HX (2007) Understanding abiotic stress tolerance mechanisms: recent studies on stress response in rice. I Integr Plant Biol 49(6): 742-750

129. Mizoi J, Shinozaki K, Yamaguchi Shinozaki K (2012) AP2/ERF family transcription factors in plant abiotic stress responses. Biochim Biophys Acta (BBA)-Gene Regul Mech 1819(2): 86-96.

130. Hail Z Rihan, Mohammed Al Issawi, Magda Al Shamari, Wondwossen Abate Woldie, Michele Kiernan, et al. (2014) The effect of molybdenum 
on the molecular control of cold tolerance in cauliflower (Brassica oleracea var. botrytis) artificial seeds. Plant Cell Tiss Organ Cult 118: 215-228.

131. Yu M, Wang YH (2006) Effects of molybdenum on the precursors of chlorophyll biosynthesis in winter wheat cultivars under low temperature. Sci Agric Sin 39: 702-708 (In Chinese).

132. Sun X, Hu C, Tan Q Gan Q (2005) Effects of molybdenum on photosynthetic characteristics in winter wheat under low temperature stress. Acta Agric Sin 32: 1418e1422 (In Chinese).

133. Al-Issawi M, Rihan HZ, Woldie WA, Burchett S, Fuller MP (2013a) Exogenous application of molybdenum affects the expression of CBF14 and the development of frost tolerance in wheat. Plant Physiol Biochem 63: 77-81.

134. Sun X, Hu C, Tan Q (2006) Effects of molybdenum on antioxidative defense system and membrane lipid peroxidation in winter wheat under low temperature stress. J Plant Physiol Mol Biol 32(2): 175.

135. Yue Y, Zhang M, Zhang J, Tian X, Duan L, et al. (2012) Overexpression of the AtLOS5 gene increased abscisic acid level and drought tolerance in transgenic cotton. J Exp Bot 63: 3741-3748.

136. Nezhadahmadi A, Prodhan ZH, Faruq G (2013) Drought tolerance in wheat. Sci World J p. 12.

137. Farooq M, Wahid A, Kobayashi N, Fujita D, Basra S (2009) Plant drought stress: effects, mechanisms and management. Sustain Agr, Springer, pp. 153-188.

138. Gill SS, Tuteja N (2010) Reactive oxygen species and antioxidant machinery in abiotic stress tolerance in crop plants. Plant Physiol. Biochem 48: 909- e930.

139. Li Y, Zhang J, Zhang J, Hao L, Hua J, et al. (2013) Expression of an Arabidopsis molybdenum cofactor sulphurase gene in soybean enhances drought tolerance and increases yield under field conditions. Plant Biotechnol J11: 747-e758.

140. Songwei Wu, Chengxiao Hu, Qiling Tan, Zhaojun Nie, Xuecheng Sun (2014) Effects of molybdenum on water utilization, antioxidative

\section{ISSN: 2574-1241}

DOI: 10.26717/BJSTR.2020.24.004104

Cheng-xiao Hu. Biomed J Sci \& Tech Res

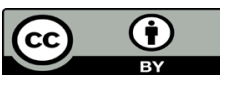

This work is licensed under Creative Commons Attribution 4.0 License

Submission Link: https://biomedres.us/submit-manuscript.php defense system and osmotic-adjustment ability in winter wheat (Triticum aestivum) under drought stress. Plant Physiology and Biochemistry 83: 365- e374.

141. Jiang M, Zhang J (2002) Water stress-induced abscisic acid accumulation triggers the increased generation of reactive oxygen species and up-regulates the activities of antioxidant enzymes in maize leaves. J Exp Bot 53: 2401-e2410.

142. Yordanov I, Velikova V, Tsonev T (2000) Plant responses to drought, acclimation, and stress tolerance. Photosynthetica 38: 171-186.

143. Mahajan S, Tuteja N (2005) Cold, salinity and drought stresses: an overview. Arch. Biochem. Biophys 444: 139-158.

144. Lu Y, Li Y, Zhang J, Xiao Y, Yue Y, et al. (2013) Overexpression of Arabidopsis molybdenum cofactor sulfurase gene confers drought tolerance in maize (Zea mays L.). PloS one 8: e52126.

145. Chatterjee C, Nautiyal N (2001) Molybdenum stress affects viability and vigor of wheat seeds. J Plant Nutrition 24: 1377-1386.

146. Jolivet P, Bergeron E, Meunier JC (1995) Evidence for sulphite oxidase activity in spinach leaves. Phytochemistry 40: 667-672.

147. Mu Zhang, Chengxiao Hu, Xiaohu Zhao, Qiling Tan, Xuecheng Sun, et al. (2012) Molybdenum improves antioxidant and osmotic-adjustment ability against salt stress in Chinese cabbage (Brassica campestris $L$. ssp. Pekinensis) Plant Soil 355: 375-383.

148. Ralf R, Mendel (2011) Cell biology of molybdenum in plants. Plant Cell Rep 30: 1787-1797.

149. Yaneva IA, Baydanova VD, Vunkova-Radeva RV (2000) Nitrate reductase activation state in leaves of molybdenum-deficient winter wheat. Journal of Plant Physiology 157: 495-501.

150. Zakhurul I, Vernichenko IV, Obukhovskaya LV, Osipova LV (2000) Influence of nitrogen, molybdenum, and zinc on the drought resistance of spring wheat. Russ Agric Sci 4:1-5.

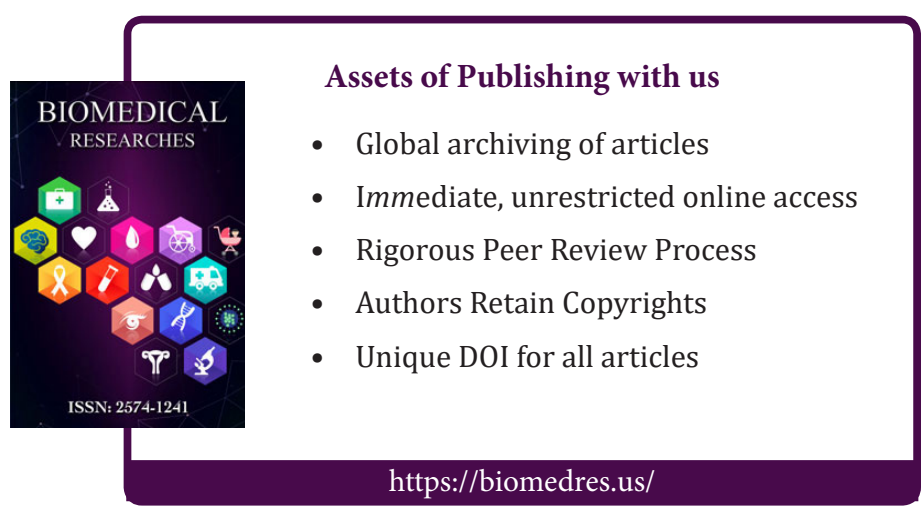

